\title{
Luiz Gastão Paes de Barros Leães
}

Titular de Direito Comercial

\section{O Professor}

Luiz Gastão Paes de Barros Leães nasceu nesta Capital aos 19 de abril de 1936. É filho do Dr. João Leães Sobrinho e de Dona Maria Cecília Paes de Barros Leães. São seus avós paternos Salustiano Soares Leães e Catharina Soares Leães, e avós maternos, Joaquim Fernando Paes de Barros Júnior e Ana Blandina de Almeida Prado Paes de Barros.

Fez o curso primário no Externato Meira e o ginasial no Colégio São Luís, nesta Cidade. Mudando-se em 1950 para o Rio de Janeiro, completou o curso científico no Colégio Santo Antônio Maria Zacarias, bacharelando-se em Direito pela Faculdade de Direito da Universidade do Rio de Janeiro, em 1961 .

Retornando à São Paulo, ingressa no Curso de Especialização em Direito Comercial, desta Faculdade, concluindo-o em 1964. Em 1967, obtém o título de Doutor em Ciências Jurídicas e Sociais, e, em 1971, o título de Livre Docente, nesta Casa.

No ano letivo de 1973/1974, estagia na Columbia Law School University, em Nova Iorque, nos Estados Unidos da América do Norte, como visiting scholar in residence.

Exerce a docência da matéria de sua especialidade, nesta Faculdade, desde 1965.

Ex-Técnico de Migração, do Instituto Nacional de Imigração e Colonização, por concurso realizado pelo DASP, em 14 de novembro de 1961. Desde 1962, é advogado militante na cidade de São Paulo, prestando assessoria jurídica a várias empresas. 


\section{4}

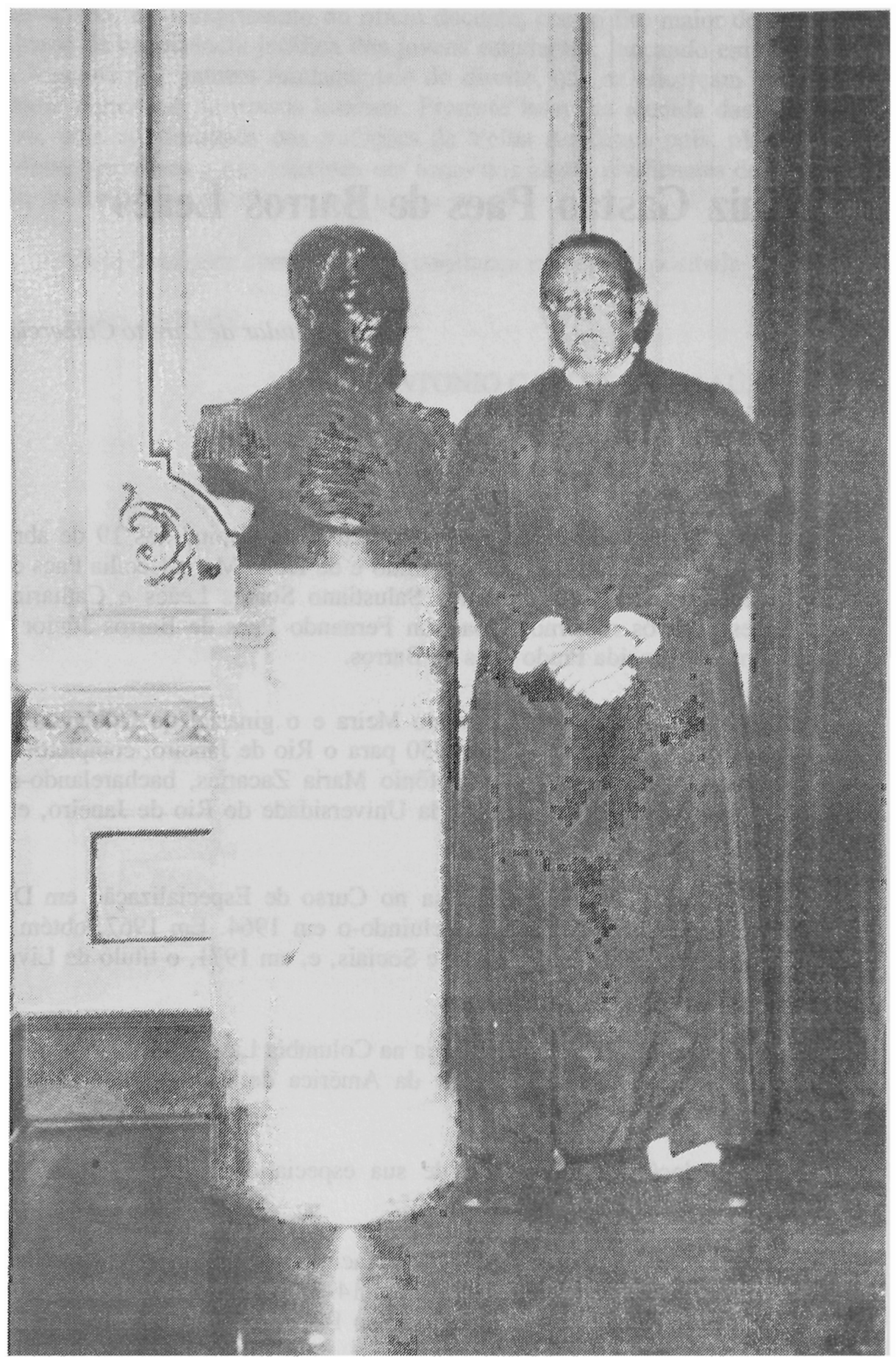


Realizou várias conferências, dentro e fora do País, tendo sido por diversas vezes o chefe da delegação brasileira nas reuniōes da Commission on International Trade Law das Organizações das Nações Unidas, em Viena e Nova Iorque.

Antigo Titular do Comitê de Questões Legais do International Iron and Steel Institute (IISI), com sede em Bruxelas, é membro do Instituto Brasileiro de Direito Comercial Comparado, anexo à Faculdade de Direito da Universidade de São Paulo, do Instituto dos Advogados de São Paulo, do Instituto Brasileiro de Direito Tributário e da International Fiscal Association.

Publicou vários trabalhos, vinculados à matéria de sua especialidade. Além de dezenas de artigos doutrináriós, palestras, comentários de jurisprudência e pareceres, são seus livros principais: 1) Ensaio sobre Arbitragens Comerciais, Rev. dos Trib., SP, 1966; 2) Do Direito do Acionista aos Dividendos, ed. Obelisco, SP, 1969; 3) Obrigação Tributária, J. Bushatsky, SP, 1971; 4) Direito Comercial: Textos e Pretextos, J. Bushatsky, SP, 1976; 5) Comentários à Lei das Sociedades Anônímas, vol. 2º, Saraiva, SP, 1980; 6) Mercado de Capitais \& "Insider Trading", Rev. dos Trib., SP, 2ª ed., 1982; 7) A Responsabilidade do Fabricante pelo. Fato do Produto, Saraiva, SP, 1987.

\section{Titularidade e Recepção no Doutoral}

Em brilhante concurso de títulos e provas, realizado entre 11 e 16 de março de 1985, o professor Luiz Gastão Paes de Barros Leães obteve a titularidade de Direito Comercial, vaga com o falecimento do Professor Oscar Barreto Filho.

Em sessão solene da Congregaçāo, realizada no salão nobre, sob a presidência do Senhor Diretor, Professor Vicente Marotta Rangel, foi introduzido no recinto pelos professores Philomeno J. da Costa e Ruy Barbosa Nogueira, e saudado em nome da Congregação pelo Professor Emérito Miguel Reale, que, de improviso, enalteceu a personalidade e a obra do novo titular.

Após a saudaçāo, o Professor Luiz Gastão Paes de Barros Leães proferiu o seu discurso de posse. 


\section{Discurso de posse}

- Excelentíssimo Senhor Diretor da Faculdade de Direito da Universidade de São Paulo, Professor Doutor Vicente Marotta Rangel,

- Excelentíssimo Senhor Professor Miguel Reale, a quem agradeço desde já as generosas palavras de saudação,

- Senhores Professores, Autoridades presentes,

- Minhas senhoras e meus senhores.

Eu não seria suficiente sincero, se destacasse, nesse momento, apenas a alegria que me invade ao ser recebido como professor titular desta Casa, pois esse contentamento vem acompanhado de um certo desconforto. Os caminhos do coração são insondáveis e os sentimentos não raro formam dentro de nós desenhos cujos significados nem sempre entendemos.

Talvez eu sinta, ao tomar assento definitivo no doutoral, como que ameaçada essa disponibilidade diferentes solicitaçōes, que sempre lutei por preservar. Pois o amargo da vida, como dizia Gide, é que sempre temos de optar, entre caminhos diferentes, por um deles, para conviver com a nostalgia daqueles que foram preteridos.

Por outro lado, ao atingir o grau máximo da carreira docente nesta Faculdade, não consigo afastar a convicção de que poderia ter feito mais e melhor para merecê-lo.

Daí por que sinto que esta cerimônia, mais do que uma amável recepção, fonte de justificado júbilo, deve ser entendida como uma espécie de solene confirmação de voto, através do qual o novo professor revalida, perante seus pares, os compromissos de fidelidade à vocação intelectual, que a sorte lhe reservou, e de dedicação à vida científica, que voluntariamente abraçou.

Na verdade, momentos como este, minhas senhoras e meus senhores, sāo ocasiões propícias à meditação e ao julgamento de si mesmo. Nessas datas definitivas, naturalmente se impõe uma pausa no tumulto de nossos dias, para concentrarmos a consciência no exame de nosso destino não só do destino cumprido, mas sobretudo do destino a cumprir.

\section{I}

Sempre me intrigou a misteriosa mola psicológica que nos anima a manter esse convívio quase promíscuo com a palavra impressa. Por que essa ob- 
sessão que nos leva a debruçar sobre escritos alheios? O que nos leva a consumir grande parte de nossas vidas junto a uma mesa, elaborando o nosso discurso em meio dos discursos de terceiros?'

Esse hábito tem, aliás, tradição venerável. Ao menos, tal como hoje o concebemos, esse convívio com os livros é contemporâneo àquilo que Burchkardt assinalou como característico da Renascença: a descoberta da própria individualidade. Nunca deixou de me comover a conhecida carta de Maquiavel, endereçada a Francesco Vettori, datada de 10 de dezembro de 1513, onde o secretário florentino fala de si mesmo algumas boas décadas antes de Montaigne eleger-se a si próprio como o núcleo de sua obra genial. Mormente a passagem onde, após relatar o seu dia de exilado em São Casciano, registra esse vício impune.

Diz ele: "Chegando à noite, de volta à casa, entro no meu escritório; e na porta dispo as minhas roupas cotidianas, sujas de barro e de lama e visto as roupas da corte ou de cerimônia, e vestido decentemente penetro na antiga convivência dos grandes homens do passado; por eles sou acolhido com bondade, nutro-me daquele que é o único aiimento que me é apropriado e para o qual nasci. Não me envergonho de falar com eles e lhes pergunto a razão das suas ações, e eles humanamente me respondem; e não sinto durante quatro horas aborrecimento algum, esqueço os desgostos, não temo a pobreza, não me perturba a morte; transfundo-me neles por completo".

Descontada uma certa ponta de frivolidade, que, dadas as circunstâncias, seria desumano nāo revelar, fica a interrogação: Trata-se de uma fuga à realidade? ou da busca de uma realidade mais autêntica? No universo da cultura, ainda profundamente imerso na galáxia gutemberguiana, tudo se dá num jogo de distanciamento e intimidade com o mundo. Os acontecimentos chegam a nós filtrados pelas diversas óticas armadas pelos discursos alheios. Se com isso os

eventos perdem a irradiaçāo direta, ganham por certo com as versões depuradas dos enganos da percepçâo. Essa mesma pessoa que confessa encontrar refúgio na circunspeç̧ão da leitura, toma como lema, para os trabalhos que nessa ocasião escreve, a busca da verità effetuale della cosa.

Não se faz necessário acrescentar que, com essa posição, o homem de cultura habita um terreno onde é frequente o risco da alienação. Donde a impe- 
riosidade de possuir consciencia crítica a fim de manter, em relação a esse universo, não a atitude passiva de beata aceitação, mas a postura metódica de permanente vigilância. Sobretudo deverá manter a flexibilidade de espírito indispensável para submeter as concepçōes alheias a exame, em função dos dados concretos recolhidos na experiência. Enfim, deve preservar a sua liberdade interior, para, paradoxalmente, nunca se desligar do meio em que vive.

Velha é a tradição da inteligência empenhada com as realidades do seu tempo. Maquiavel é um típico exemplo de engajamento, pois a descoberta do foro íntimo, em sua época, năo significava, para ele, a perda do "espaço público" da individualidade. Com efeito, na atmosfera inquieta do Renascimento, a sua obra é dominada por um profundo sentimento nacional.

Até o século $\mathrm{XV}$, desenvolve-se, com a derrocada da economia feudal, o processo de ascenção do capitalismo. Surgem, na Europa Ocidental, os novos estados nacionais. As soberanias locais vão sendo absorvidas pelo fortalecimento das monarquias e pela centralização progressiva das instituições políticas - reflexo das forças expansivas do regime econômico em ascenção. Mas se em França e na Inglaterra o poder monárquico pôde, desde o início, dominar as tendências centrípetas, as florescentes cidades italianas, pelo contrário, atingiram uma independência completa que inibia a unificação.

O secretário florentino, porém, procura os meios próprios para plasmá-la e discute as formas de governo mais apropriadas à sua execução. $O$ seu pequeno e famoso livro, O Príncipe, tão exaltado quão denegrido, considerado sibilino em seus fins, apesar de cristalino na forma, nada mais é do que um instrumento para lograr a unidade política de seu país.

Independentemente porém do que veio a significar, esse pequeno grande livro reflete as condições nas quais e para os quais foi escrito: a reforma política, o livre exame dos fatos históricos, o ataque às tradiçōes medievais, a instituição do êxito como única medida do poder do príncipe, enfim, a ruptura do temporal como o espiritual. Mas o que é mais significativo: revela a consciência da responsabilidade da inteligência. Tal conclusão é tanto mais curiosa quando se pensa que, com essa obra insólita, o autor conquistou uma fama deplorável. Aliás, justificada, pois a leitura de certas páginas não deixa de produzir calafrios morais, mesmo no leitor mais realista que, admitindo a crueza do mundo político, não abdica da idéia de vinculá-lo a uma atividade dirigida para o bem

comum. Propcsitadamente escolhi esse exemplo, que sob certo ângulo é um exemplo terrivelmente perverso, porque gostaria de me demorar sobre esse topico. 
Façamos agora um salto de quatro séculos. Vejamos um texto de 1937. Trata-se da novela L'Espoir, de André Malraux, cujo tema central é, como se sabe, a guerra civil espanhola. Nela se confrontaram, numa forma cruenta, as duas Espanhas, uma popular e outra liberal, uma apoiada pelos católicos, catalães e bascos, outra composta pelo clero e pelo exército, apoiada pela Itália fascista e pela Alemanha hitleriana. Foi de certa forma a visão antecipada da tragédia que seria a segunda conflagração mundial. Nesse país banhado de sangue, levitava figura profundamente solitária de Miguel de Unamuno, lente de grego e reitor da Universidade de Salamanca, que reagira, sem complacência, contra as chacinas realizadas por ambas as facçōes, certo de que é inadmissível qualquer prática que coloque as idéias, essas coisas abstratas, acima da vida humana.

Comentando a solidão de Unamuno, diz o revolucionário Garcia, um dos personagens de romance: "O intelectual (diz ele) é o homem dos matizes, das valoraçôes, da verdade, da complexidade. Por isso é, por definição, antimaqueu. Ora, todas as formas de ação são maniqueistas, pois toda ação paga seu tributo ao diabo: esse elemento maniqueu é mais intenso ainda quando as massas estão envolvidas. Todo revolucionário é um maniqueu inato, e o mesmo se pode dizer da política, de todo tipo de política". Difícil nāo ver essa reflexão feita pela persona a figura empírica do artista - escritor de gênio e homem de ação - num momento de insegurança e perplexidade. Pois aí se defrontam duas posiçōes extremas de compromisso: a posiçāo do revolucionário (e a do conselheiro de príncipes), que se empenha na ação política e a posição do espectador e participante, que vê no exercício crítico o seu modo próprio de se empenhar.

Na primeira posição, a postura é determinada pela convicção, altamente suspeita, de que, em política, a consciência e a ação se interpenetram de tal forma, que seria inconcebível uma sem a outra, consubstanciando a tomada de consciência da dimensāo política uma ação material: latente, ameaçadora ou ostensiva.

Ora, mesmo que se aceite essa interdependência entre consciência e ação políticas, não quer isso dizer, por certo, que esta deva deixar que suas diretrizes sejam governadas pelas circunstâncias. Nesse ponto, a ação política não se diferencia de qualquer açāo prática; a eficiência bruta não justifica que se tergiverse com o equacionamento moral.

O comentário sardônico do revolucionário Garcia, portanto, não procede, mas inegavelmente lança luz sobre a função política do homem de cultura. Tu-

do somado, a posição crítica de Unamuno não significa inação, visto que a função política do intelectual, qua talis, não se explicita na atividade material, mas 
no exercício crítico dos fins específicos da ordem política, que pode coexistir ou não com a ação desenvolvida como homem social.

De resto, se fizermos um exame retrospectivo sobre o lugar ocupado pelo homem de cultura em relação à coisa pública, concluiremos que a missão de esclarecimento político sempre se inscreveu no seu estatuto. Ao defenderem Calas e Dreyfus, como já observou alguém, Voltaire e Zola não tiveram que descer à arena: por vocação, já estavam lá.

$\mathrm{Na}$ década de 30, época em que apareceu o romance de Malraux, viva era a discussão sobre o dever da inteligência. Num panfleto publicado em 1927, que teve grande repercussão em França, e fora dela, Julien Benda falou sobre a "traição dos clérigos", i. é, dos intelectuais, que vinham comprometendo a sua missão de depositários e promotores dos valores espirituais, para colocarem-se a serviço dos valores contingentes. É de 1929 a Ideologie und Utopie, onde Karl Mannheim atribuia aos intelectuais, considerados como indivíduos desligados de qualquer classe social, o escopo de criar a síntese das ideologias contrapostas e assim promover o avanço da sociedade. E Gramsci em algumas anotações dessa época (Opere, III, Gli intellectuali e l'organizzazione della cultura) fala no "intelectual orgânico" surgido com o novo bloco histórico, que transvia o pensamento em relação à atividade política, consagrando a concepçāo substitutiva do tecnocrata, que eliminaria a responsabilidade política em favor de uma atividade exclusivamente operacional.

Essa discussāo, em grande parte anacrônica, mas que recrudesceria surpreendentemente nos anos do pós-guerra, na Europa, e até no chienlit de 1968, e que agora modestamente aqui renovo, tem o condão de enfatizar que, no complexo processo geral da experiência humana, a que chamamos cultura, vivem, em íntima correlação, as diversas formas de experiência (artística, econômica, política), sendo impossível isolar in vitro cada uma dessas dimensōes naturais do ser humano.

Nessa perspectiva, o papel de homem de cultura na sociedade não é determinado numa instância exterior a si mesmo, mas, como diz Raymond Aron, numa opção pessoal, numa decisāo existencial sobre si mesmo.

\section{III}

Ora, essa decisão, ao longo da história, quem primeiro a tomou, como reconheceu Foucault, foi, de fato, uma figura exemplar: o homem do Direito, 
portador da lei e militante da equidade. Pois as grandes lutas políticas, mormente as que se travaram a partir do século XVIII, giraram em torno "daquilo que é justo". O homem da lei sempre foi visto como aquele que opõe a universalidade da justiça ao arbítrio. Daí porque a possibilidade de um poder político, com doses mínimas de legitimidade, era identificada e compreendida, durante a emergência do constitucionalismo clássico, a partir das praxis jurídica.

$\mathrm{Na}$ estrutura do liberalismo tradicional, a individualidade compendiava, segundo Jellinek, duas situações: o status civitatis e o status activae civitatis, vale dizer a de membro autônomo da coletividade e a de membro participante dos destinos políticos da coletividade.

Se assim foi na segunda metade do século XVIII, e no decorrer do século XIX, quando o pensamento iluminista imaginava ser possível o equilíbrio social fundado na racionalização do poder político por via do seu enquadramento jurídico-formal, com maior razão deverá sê-lo no século, onde o fenômeno jurídico se move num espaço de crescente complexidade, acentuado antagonismo de classes e de dissimétricas relaçōes de poder. Nesse contexto, o Direito passa a ser encarado como uma técnica social suscetível de absorver as contradições inerentes a essa sociedade, desde que conte com um ágil poder político, capaz de dar respostas aos problemas sócio-econômicos de nossa época, alimentados por intensas clivagens ideológicas.

Daí o duplo papel do jurista, acentuado por Bobbio: o jurista conservador de um corpo de regras já dadas, de que é o depositário, e o jurista criador de normas que transformam, integram e inovam o sistema, do qual mais do que o recipiendário, é o colaborador ativo e, sobretudo, crítico. O direito positivo é aí tomado não só na sua função estabilizadora de controle social, mas, principalmente, na sua função promocional, como instrumento de modificação da realidade social.

Essa função promocional ou funcional do direito não é, por certo, nova: nova é talvez a sua extensão. A experiência jurídica é um processo contínuo e sem fim de adaptações de valores e fatos em estruturas normativas voltadas às necessidades da mudança social. O ordenamento deve, assim, ser articulado a fim de que possa desempenhar o papel de caixa de ressonância dos valores dominantes, que politicamente o legitimam.

Nesse contexto, adquire relevo a missão do professor de Direito. No ensino ou na pesquisa, na atuação junto ao espírito jurídico das novas geraçōes ou na intimidade da biblioteca, a ele cabe o privilégio (e o dever) de enfrentar os desafios do tempo, propondo soluçōes jurídicas novas. A linha de combate - 
o front - da luta pelo Direito é historicamente móvel, mas é para ele que deve transportar-se o espírito do jurista, comprometendo, nesse combate, as suas convicções e as suas aspirações mais íntimas. Enfim, o seu "projeto vital", convencido de que é esse empenho que lhe dá a têmpera das melhores virtudes, pois como diz Jhering, "a luta pelo Direito é a poesia do caráter". 